\title{
REESTRUTURAÇÃO, REESCALONAMENTO E A QUESTÃO URBANA*
}

\author{
Neil Brenner**
}

Tradução: Daniel Sanfelici; Karen Heberle

\begin{abstract}
Resumo: No contexto dos debates recentes sobre escala e teoria socioespacial, esse texto explora alguns dos limites e possibilidades das interpretações escalares dos padrões de reestruturação urbana e regional relacionados ao pós-fordismo e ao período referente ao início do século XXI. Inicio assinalando algumas das premissas escalares que embasaram debates sobre a questão urbana nos anos 1970 e 1980. Eu então sugiro que, desde os anos 1990, a questão urbana tem sido repensada conceitualmente em termos reflexivamente escalares, no contexto de debates sobre a reestruturação urbana e regional mundial. A problemática da escala geográfica - sua organização espacial, sua produção social, sua contestação política e reconfiguração histórica - foi, portanto, inserida no âmago da questão urbana. As seções seguintes destacam a utilidade da perspectiva escalar para pensar as transformações urbanas contemporâneas, mas salientam a dificuldade persistente de definir seu conteúdo analítico distintivo. Confronto esse problema oferecendo uma série de proposições gerais com o propósito de especificar os parâmetros conceituais determinados das questões de escala e, por implicação, dos processos de reescalonamento. A teorização proposta envolve um estreitamento conceitual das questões de escala: os conceitos de escala não devem ser confundidos com aqueles de espaço, lugar, território ou redes. Consequentemente, as geografias cambiantes e polimórficas da reestruturação urbana não podem e não devem ser conceituadas inteiramente em termos escalares. Eu argumento, porém, que os conceitos escalares permanecem ferramentas essenciais para decifrar algumas das dimensões mais importantes das transformações urbanas contemporâneas.
\end{abstract}

Palavras-chave: escala; reescalonamento; reestruturação urbana; teoria espacial; questão urbana.

\section{RESTRUCTURI NG, RESCALI NG AND THE URBAN QUESTION}

\begin{abstract}
Against the background of recent debates on scale and sociospatial theory, this essay explores some of the limits and possibilities of scale-attuned interpretations of after-Fordist and early 21st century patterns of urban and regional restructuring. I begin by excavating some of the scalar presuppositions that underpinned debates on the urban question in the 1970s and 1980s. I then suggest that, since the 1990s, the urban question has been reconceptualized in reflexively scalar terms in the context of debates on worldwide urban and regional restructuring. The problematic of geographical scale - its spatial organization, its social production, its political contestation and its historical reconfiguration - has thus been inserted into the very heart of the urban question. Subsequent sections affirm the usefulness of a scalar perspective on contemporary urban transformations, but underscore the persistent difficulty of defining its distinctive analytical content. I confront this problem by offering a series of general propositions intended to specify the determinate conceptual parameters of scale questions and, by implication, rescaling processes. The proposed theorization entails a conceptual narrowing of scale questions: concepts of scale should not be conflated with those of space, place, territory, or networks. Consequently, the churning, polymorphic geographies of urban restructuring cannot and should not be conceptualized entirely in scalar terms. I argue, however, that scalar concepts remain essential tools for deciphering some of the key dimensions of contemporary urban transformations.
\end{abstract}

Key Words: scale; rescaling; urban restructuring; spatial theory; urban question.

\footnotetext{
* Esse texto foi originalmente publicado na revista Critical Planning, número 16, em 2009. A Geousp agradece os editores da Critical Planning pela permissão para tradução e publicação do presente artigo.

** Neil Brenner é professor de Teoria Urbana na Harvard Graduate School of Design e coordenador do Urban Theory Lab. Suas áreas de pesquisa incluem estudos urbanos críticos, teoria do Estado, teoria socioespacial e economia geopolítica.
} 


\section{NTRODUÇÃO}

\section{Espaços de reestruturação}

Escrevendo no final da década de 1970, Henri Lefebvre (2009 [1979], p. 190) afirmava que estava em curso uma "explosão generalizada de espaços", em que as geografias pretéritas do capitalismo e do poder de Estado estavam sendo dramaticamente recosturadas. A expressão "explosão" (l'éclatement) aparece frequentemente, nos escritos de Lefebvre desse período, denotando um profundo desarranjo não apenas das práticas, das instituições e das ideologias estabelecidas, mas também dos espaços nos quais e por meio dos quais essas últimas se constituem. Portanto, em paralelo à irrupção (l'irruption) associada aos movimentos de Maio de $68 \mathrm{em}$ Paris (Lefebvre, 1969 [1968]), Lefebvre fala de uma série de explosões que estavam, segundo ele, reverberando por todo 0 capitalismo mundial nesse período - por exemplo, a explosão da cidade histórica, das grandes cidades, dos espaços metropolitanos, das regiões, das relações centro-periferia, dos espaços pretéritos, dos limites e das fronteiras; bem como da razão, da família, da nação, da economia e da história, do stalinismo e mesmo do marxismo (Lefebvre, 2009 , p. 90, p. 104 , p. 109 , p. 118 , p. 186 , p. 214 , p. 236 , p. 264). Em outro momento, Lefebvre lançou sua famosa proposição de que uma dinâmica simultânea de "implosãoexplosão" estava transformando as geografias urbanas estabelecidas em meio a uma crescente generalização dos processos de urbanização nos espaços local, regional, nacional e, por fim, mundial. No início do século XXI, após várias décadas de trabalho conjunto de urbanistas e geógrafos para redefinir de forma decisiva o léxico da teoria socioespacial, o uso que Lefebvre faz de termos como l'irruption, l'éclatement e l'implosion-explosion pode parecer um pouco caótico, impreciso e quiçá excessivamente apocalíptico. Todavia, mesmo que o discurso da teoria socioespacial tenha se tornado mais diferenciado e, em alguma medida, mais preciso, as ideias iniciais de Lefebvre ainda soam verdadeiras no que se refere à realidade subjacente do capitalismo moderno e tardio. O tecido do espaço social continua sendo recosturado mediante diversos processos de reestruturação discutidos nessa edição da revista Critical Planning. Como reconheceu Lefebvre no limiar da década de 1970, o espaço está sempre sendo produzido e transformado sob o capitalismo; ele nunca é uma realidade fixa, estática ou préestabelecida. Nesse sentido, a noção lefebvriana de "explosão de espaços" e os escritos mais recentes sobre a reestruturação urbano-regional voltam-se ambos para a mesma problemática social e política. Pouco mais de duas décadas atrás, Soja (1987, p. 178) sintetizava essa problemática em termos paradigmáticos:

A reestruturação transmite a noção de uma ruptura com tendências seculares e de uma mudança em direção a uma ordem e uma configuração significativamente diferentes da vida social, econômica e política. Evoca, pois, uma combinação sequencial de destruição e tentativa de reconstrução, provenientes de certas deficiências ou debilidades na ordem estabelecida que impedem adaptações convencionais e requerem, por sua vez, significativa mudança estrutural [...]. A reestruturação origina-se na crise e em um conflito entre o velho e o novo, entre uma ordem preterida e uma ordem 'projetada'. Esse processo 
não é mecânico ou automático, nem seus resultados são pré-determinados [...]. A reestruturação sugere fluxo e transição, posturas ofensivas e defensivas, uma mescla complexa de continuidade e mudança.

Desde o início dos anos 1980, a maior parte dos trabalhos mais interessantes no amplo e heterogêneo campo dos estudos urbanos e regionais críticos tentou decifrar a "mescla complexa de continuidade e mudança" relacionada com esses processos de reestruturação ocorridos nos anos turbulentos que se seguiram ao fim Fordismo Norte-Atlântico, bem como suas causas, expressões e implicações. Como esse campo de pesquisas indica, a problemática da reestruturação relaciona-se com uma ampla gama de questões teóricas, empíricas e políticas fundamentais no âmbito dos estudos urbanos e regionais e na prática de planejamento crítico (STORPER; SCOTT, 1992). Por exemplo: os processos de reestruturação contemporâneos prenunciam uma nova configuração do desenvolvimento capitalista global, ou uma política continuada de administração de crises, experimentações regulatórias e medidas improvisadas? Esses processos de reestruturação adquirem formas territoriais, locais e escalares específicas e, se sim, quais são suas causas, contornos e ramificações? Como esses processos, em suas formas espacialmente seletivas, são moldados por arranjos institucionais, estratégias políticas e forças sociais? Poderiam os processos de reestruturação ser conduzidos por instituições progressistas e movimentos sociais no sentido de promover formas de organização político-econômicas democratizadas, socialmente justas e ambientalmente sustentáveis? Tendo em vista a importância das considerações espaciais para cada uma dessas indagações, sua persistente urgência intelectual e política ajuda a explicar em grande medida a "reafirmação do espaço na teoria social crítica" que foi notoriamente postulada duas décadas atrás por Soja (1989). Certamente, os debates sobre a conceituação do espaço social desde os anos 1970 foram influenciados por diversas correntes filosóficas e teórico-sociais, incluindo a dialética hegeliana, o marxismo, a fenomenologia, a hermenêutica, o estruturalismo, o feminismo, a psicanálise e o pós-estruturalismo. Mas a apropriação desses legados foi fortemente mediada pelos inumeráveis desafios de decifrar os processos explosivos e multiescalares de reestruturação socioespacial que vêm reverberando por todo o sistema capitalista mundial, em todas as escalas espaciais, desde o colapso da ordem Fordista Norte-Atlântica. Na esteira das mais recentes e igualmente explosivas tendências de crise que estão rediferenciando as geografias já fortemente instáveis e desiguais estabelecidas durante as três décadas que sucederam o colapso do Fordismo NorteAtlântico, a tarefa de decifrar as paisagens ininterruptamente cambiantes do capitalismo permanece mais urgente do que nunca, tanto intelectual quanto politicamente.

Mas como, exatamente, conceituar esses espaços de reestruturação em constante ebulição? Os leitores da Critical Planning sabem que essa questão é tão controversa hoje como era há dezesseis anos, quando do surgimento da revista. Por um lado, existe hoje uma infinidade de livros e de coletâneas que confronta fecundamente o problema de teorizar o espaço social, sua produção e sua transformação sob o capitalismo moderno. Incluem-se aí não apenas os já mencionados escritos de Lefebvre e Soja, mas também, evidentemente, aqueles de pesquisadores como Harvey (1982), Massey (1985), Dear e Scott (1982), Scott e Storper (1986) e muitos outros vinculados à chamada "escola 
de Los Angeles" (para um panorama, ver SOJA, 2000). Por outro lado, pode-se afirmar que a maior parte das pesquisas teoricamente reflexivas no campo dos estudos urbanos e regionais críticos após a década de 1980 enfocaram menos na problemática do espaço social enquanto tal, do que em diversas (e mais específicas) dimensões e dinâmicas de reestruturação socioespacial contemporânea. Essas incluem, por exemplo, os processos de produção do lugar, de aglomeração, de localização, de descentralização e de reconfiguração das divisões espaciais do trabalho; a tensão entre fixidez e mobilidade geográfica e a concomitante construção e desmantelamento de arranjos espaciais; processos de territorialização, desterritorialização e reterritorialização; tendências de regionalização e o desenvolvimento espacial desigual das relações político-econômicas; e, mais recentemente, a produção da escala geográfica e o processo associado de reescalonamento ${ }^{1}$.

É essa última dimensão da análise socioespacial - que, em outro momento, denominei como a "questão de escala" (BRENNER, 2004) - que constitui meu objetivo central nesse artigo. Meu interesse em questões de escala foi estimulado não apenas pela leitura das pioneiras análises acerca da explosão contemporânea dos espaços, sensíveis à questão da escala, feitas por Henri Lefebvre, mas também pelos escritos dos teóricos da cidade global (FRIEDMANN; WOLF, 1982; TAYLOR, 1995), os teóricos da regulação (JESSOP, 1998; LIPIETZ, 1994; PECK; TICKELL, 1994) e as abordagens precursoras de Neil Smith (1992)

\footnotetext{
${ }^{1} \mathrm{O}$ termo original, de difícil tradução, é rescaling, substantivo que Brenner utiliza para designar o processo de reorganização/rearranjo dos vínculos entre as escalas geográficas. Brenner utiliza também os verbos "to scale" e "to rescale", que traduzimos, respectivamente, por "escalonar" e "reescalonar" e suas derivações. N.T.
}

e Erik Swyngedouw (1992) sobre o que eles designaram, em determinado momento, por "política de escala" e "glocalização". Esses escritos, bem como um grande número de contribuições teóricas e empíricas subsequentes no âmbito da geopolítica econômica crítica, fortaleceram o interesse na dimensão escalar dos processos de reestruturação sob o capitalismo histórico e contemporâneo (para um panorama recente, ver MARSTON, 2000). Em vez de conceber a constituição escalar do capitalismo moderno - sua diferenciação entre unidades geográficas locais, regionais, nacionais, supranacionais e global - como um traço préestabelecido da vida social, tais configurações escalares são agora entendidas como arenas e produtos produzidos, contestados e, portanto, maleáveis das relações políticoeconômicas. Igualmente, contribuições seminais à economia geopolítica, à teoria do Estado, aos estudos urbanos e regionais, aos estudos sobre movimentos sociais, e à geografia ambiental perscrutaram diversas formas de transformação escalar contemporânea, ou reescalonamento, em que os ordenamentos escalares pretéritos estão sendo gradativamente confrontados, desestabilizados e reorganizados (KEIL; MAHON, 2009). Evidentemente, as ciências sociais há muito tempo continham premissas acerca da constituição escalar dos processos político-econômicos - desde a acumulação de capital e a regulação estatal até a urbanização e mobilização sociopolítica. Porém, esses avanços interdisciplinares mais recentes indicam que a questão da escala está sendo, hoje, confrontada com reflexividade metodológica sem precedentes, em um contexto de debates mais amplos sobre a reestruturação capitalista mundial. Consequentemente, as considerações escalares agora figuram explicitamente nas explicações mais espacialmente sensíveis e 
metodologicamente reflexivas da

reestruturação capitalista contemporânea.

Tendo isso em vista, o restante desse artigo explora alguns dos limites e possibilidades de interpretações escalares dos padrões de reestruturação urbana e regional característicos do pós-fordismo e do início do século XXI. Inicio rastreando algumas dos pressupostos escalares implícitos nos debates, ao longo dos anos 1970 e 1980, acerca do que Castells (1977 [1972]) conhecidamente denominou de "questão urbana". Eu, então, sugerirei que, desde os anos 1990, a questão urbana tem sido reconceituada em termos reflexivamente escalares no contexto de debates sobre a reestruturação urbana e regional mundial. As seções subsequentes propugnam a pertinência da perspectiva escalar acerca das transformações urbanas contemporâneas, mas enfatizam a persistente dificuldade de definir seus conteúdos analíticos distintivos. Enfrentarei esse problema oferecendo uma série de proposições gerais com o objetivo de especificar os parâmetros conceituais precisos das questões de escala e, por extensão, dos processos de reescalonamento.

A teorização proposta implica um estreitamento conceitual das questões de escala: os conceitos de escala não devem ser confundidos com os de espaço, lugar, território ou redes. Portanto, as geografias cambiantes e polimórficas da reestruturação urbana não podem e não devem conceituadas inteiramente em termos escalares. Meu argumento, todavia, é o de que os conceitos escalares permanecem ferramentas essenciais para desvendar algumas das dimensões fundamentais das transformações urbanas contemporâneas.

\section{ESPAÇO, ESCALA E A QUESTÃO URBANA}

Desde o início da década de 1970, os

debates sobre a questão urbana concentraram-se fortemente na conceituação de espaço na investigação sobre as cidades (GOTTDIENER, 1985). Porém, em seus esforços para conceituar a espacialidade urbana, os teóricos urbanos incorporaram, necessariamente, diversas premissas acerca da especificidade da escala urbana da organização socioespacial (em contraposição, por exemplo, com as escalas regional, nacional e global). A fim de esmiuçar esse argumento e suas implicações para a teoria urbana, pretendo revisitar brevemente algumas das premissas escalares que embasaram debates anteriores acerca da questão urbana. No seu trabalho clássico $A$ questão urbana, Manuel Castells (1977 [1972]) criticou a Escola de Chicago de Sociologia Urbana por não ter logrado compreender a especificidade histórica da forma urbana sob o capitalismo. Contrariando essa “ideologia urbana” universalista, Castells se pôs a delimitar o papel do "sistema urbano" enquanto uma estrutura determinada no seio do modo capitalista de produção. Ao fazê-lo, Castells implicitamente discerniu duas dimensões básicas do urbano, que para nossos propósitos podemos tratar como sua dimensão escalar e sua dimensão funcional. O aspecto escalar do urbano refere-se à materialidade dos processos sociais organizados na escala urbana, em oposição às escalas supraurbanas. $\mathrm{Na}$ terminologia de Castells (1977, p. 445-450), as escalas são apreendidas como as "unidades espaciais" diferenciadas das quais o capitalismo é constituído. O aspecto funcional do urbano, foco mais explícito de Castells em A questão urbana, diz respeito não apenas ao contexto geográfico ou abrangência territorial dos processos sociais, mas ao seu papel funcional ou "conteúdo social" (CASTELLS, 1977, p. 89, p. 235). De 
acordo com o conhecido argumento de Castells (1977, p. 235-237, p. 445), a especificidade da "unidade espacial" urbana não poderia ser teoricamente definida com relação às suas funções ideológica, políticojurídica ou produtiva, mas apenas em termos de seu papel como lócus da reprodução da força de trabalho. A essência da posição de Castells, portanto, reside em sua tentativa de definir a escala geográfica em relação à sua função social. Castells reiteradamente reconheceu a existência de processos sociais múltiplos ocorrendo nas cidades capitalistas, mas afirmava que apenas o consumo coletivo era funcionalmente específico à escala urbana. A tentativa de Castells de espacializar o estruturalismo althusseriano se amparava, portanto, em um entendimento das escalas geográficas enquanto expressões espaciais de funções sociais.

Castells (1976) começou a modificar sua posição imediatamente após a publicação de A questão urbana, mas esse trabalho continuou a exercer uma influência pronunciada sobre as formas de conceituar a escala urbana no âmbito dos estudos urbanos. A crítica de Peter Saunders (1986) ao trabalho de Castells ilustra apropriadamente o alcance dessa influência. O núcleo da crítica que Saunders dirige a Castells consiste em sua rejeição da noção de que qualquer processo social que ocorra na cidade seja, em um sentido necessário, funcionalmente específico a essa escala geográfica. Essa observação levou Saunders a enxergar a organização espacial urbana como apenas um resultado contingente $e$, portanto, como um fundamento conceitual equivocado para lidar com a questão urbana. Entretanto, ao chegar a essa conclusão, Saunders implicitamente adotou o critério de Castells da especificidade funcional como o âmago teórico da questão urbana. Foi essa premissa subjacente que permitiu a Saunders invocar o caráter supraurbano dos processos sociais localizados na cidade como justificativa para descartar a possibilidade de uma definição espacial coerente do urbano. A proposição alternativa de Saunders (1986) de definir a sociologia urbana como o estudo dos processos de consumo conservou o rótulo "urbano" somente como uma "questão de convenção". Saunders tornou, assim, a dimensão urbana da sociologia urbana inteiramente acidental, uma escolha aleatória da escala geográfica.

Em que pese suas conclusões em direções opostas, ambas as posições no debate Castells/Saunders fundamentavam-se em duas premissas compartilhadas acerca do papel da escala geográfica na questão urbana. Em primeiro lugar, ambos os autores concebiam a escala urbana como o núcleo empírico auto-evidente da questão urbana. Em razão de sua preocupação decisiva com o conteúdo funcional do urbano, Castells e Saunders reduziram seu aspecto escalar - a existência de "unidades espaciais" distintamente urbanizadas no seio de um sistema capitalista global desigualmente desenvolvido - a um fato empírico préestabelecido, em vez de concebê-lo como um problema teórico à parte. Consequentemente, nenhum dos autores conseguiu analisar explicitamente as formas por meio das quais a escala urbana é socialmente produzida ou, ainda mais explicitamente, considerando o ponto de vista privilegiado proporcionado pelo período pós1980, a possibilidade de sua transformação histórica. Em segundo lugar, os argumentos tanto de Castells quanto de Saunders amparam-se em uma concepção de escala geográfica que podemos denominar de "soma zero" [zero-sum] - a noção de que as escalas operam como estruturas mutuamente excludentes, e não mutuamente constitutivas, das relações sociais. Sob esse 
ângulo, tanto Castells quanto Saunders insinuaram que as escalas geográficas supraurbanas seriam meros parâmetros exteriores para a questão urbana. Contrariamente a isso, como veremos em breve, as interconexões entre as escalas urbana e supraurbana são hoje frequentemente consideradas como intrínsecas ao próprio conteúdo da questão urbana.

Inúmeras alternativas ao trabalho inicial de Castells foram elaboradas entre o final dos anos 1970 e início dos 1980, à medida que diversos pesquisadores tentavam redefinir a especificidade do urbano. A tarefa primordial, desse ponto de vista, consistiu em identificar processos sociais que se atrelavam intrinsecamente, mas não exclusivamente, à escala urbana. Assim, as cidades eram analisadas como sítios geográficos multidimensionais onde, por exemplo, a produção industrial, os mercados de trabalho locais, as configurações de infraestrutura, as relações entre firmas, os sistemas de uso do solo urbano e os processos de consumo se aglomeravam. Do tratamento que David Harvey (1989), de uma perspectiva da lógica do capital, concede ao problema do ambiente construído urbano, passando pela teorização neo-ricardiana de Allen J. Scott (1980) sobre o nexo do solo urbano, até a análise pósweberiana de Michael Storper e Richard Walker (1989) sobre a aglomeração industrial e desenvolvimento territorial, essas abordagens substituíram o critério de especificidade funcional, estabelecido por Castells, por um critério de especificidade escalar (para um panorama dessa discussão, ver SOJA (2000)). O núcleo analítico da questão urbana não era mais a unidade funcional do processo urbano mas, antes, o papel da escala urbana como uma materialização geográfica multifacetada das relações sociais capitalistas. Na realidade, a perspectiva de Castells fora invertida. Em oposição à sua concepção das escalas como expressões espaciais de funções sociais, as relações sociais do capitalismo eram agora analisadas em função de seus padrões específicos de aglomeração e territorialização na escala urbana. Essas análises multifacetadas da espacialidade urbana logo convergiram para explorações mais abrangentes da produção do espaço e da configuração espacial sob o capitalismo. A formulação de David Harvey (1982; 1989), fundamentada no materialismo históricogeográfico, acerca da solução espacial [spatial fix] ilustra essa tendência. Em seus escritos dos anos 1980, Harvey continuou a conceber a escala urbana como um substrato geográfico primordial para o processo de acumulação, elaborando uma periodização do desenvolvimento capitalista baseada em sucessivas formas históricas da urbanização. Ao mesmo tempo, Harvey começou a conceituar de forma mais explícita o papel dos espaços e processos supraurbanos - por exemplo, as divisões regionais do trabalho, os arranjos institucionais nacionais, os regimes de acumulação supranacionais e as condições do mercado mundial - como prérequisitos geográficos primordiais para cada solução espacial [spatial fix] histórica do capitalismo. Estratégias metodológicas análogas foram elaboradas por outros pesquisadores, como Doreen Massey, Neil Smith, e Ed Soja, que alicerçavam a discussão da questão urbana em uma interpretação da espacialidade capitalista nas escalas supraurbanas, seja com relação às mudanças na divisão espacial do trabalho, aos padrões de desenvolvimento espacial desigual, ou às formas de reestruturação induzidas pela crise. Três aspectos desses debates merecem destaque aqui. Em primeiro lugar, na medida em que essas análises da espacialidade urbana 
desembocaram em uma ampla gama de questões supraurbanas - a questão regional, a problemática do desenvolvimento desigual, o debate centro-periferia, etc - a coerência da questão urbana foi profundamente abalada (SOJ A, 1989, p. 94-117). Se as explorações da questão urbana haviam contribuído de modo crucial para a abrangente espacialização da economia política marxiana, a tendência mais recente parecia ser a de superação da própria questão urbana, relegando o espaço urbano a um simples subtema em meio ao problema mais abrangente das geografias históricas desiguais do capitalismo. Em segundo lugar, essas análises introduziram concepções de escala geográfica mais multidimensionais do que aquelas que haviam sido, anteriormente, utilizadas. As escalas não eram mais vinculadas a funções sociais unitárias, mas eram consideradas, cada vez mais, como cristalizações de processos econômicopolíticos sobrepostos e variados. Em terceiro lugar, não obstante esse avanço metodológico, a historicidade das escalas geográficas foi reconhecida somente de uma maneira relativamente limitada. O capital, dizia-se, saltava continuamente entre as escalas urbana, regional, nacional e global em busca de novas fontes de mais-valia, mas a possibilidade de que as hierarquias escalares estabelecidas e de que as relações interescalares pudessem ser submetidas a uma reestruturação não foi sistematicamente explorada. Foi apenas nos anos 1990, com a disseminação da pesquisa sobre as dimensões urbanas da globalização econômica, que tratamentos conceituais historicamente mais dinâmicos da escala geográfica e das configurações interescalares foram elaborados no seio dos estudos urbanos críticos.

\section{A QUESTÃO URBANA COMO ESCALA?}

A questão urbana continuou a suscitar debates intensos nos anos 1990, mas seu significado foi sendo redefinido no contexto das discussões acerca dos processos globais de reestruturação urbana e regional. Em contraste com as concepções anteriores do urbano enquanto uma entidade escalar relativamente evidente, os pesquisadores contemporâneos depararam-se com profundas transformações na organização institucional e geográfica não apenas da escala urbana, mas também das hierarquias escalares mundiais e das redes interescalares nas quais as cidades estão imbricadas. Sob essas circunstâncias, os pesquisadores começaram a repensar conceitualmente a questão urbana de forma a relacioná-la de modo mais direto com diversos processos de reescalonamento supraurbanos.

Essa reorientação metodológica pode ser ilustrada com referência a diversas vertentes da pesquisa urbana e regional atual. Em primeiro lugar, os teóricos da cidade global e os geógrafos industriais puseram ênfase na crescente importância estratégica das relações sociais travadas no lugar, do processo de localização, e da concentração territorial como pré-requisitos geográficos basilares para as transações econômicas (KNOX; TAYLOR, 1995). Sob esse ponto de vista, a escala urbana opera como um nó local no interior de circuitos globalmente organizados de acumulação de capital, enquanto que a escala global é, por sua vez, constituída mediante redes de cidades e cidades-regiões interconectadas. Em segundo lugar, muitos autores analisaram as transformações profundas nas relações tanto horizontais como verticais estabelecidas entre as cidades, um processo que se manifesta, por exemplo, na consolidação de novas hierarquias globais urbanas, nos acelerados fluxos informacionais, financeiros 
e migratórios entre as cidades, na construção de novas infraestruturas interurbanas mundiais de telecomunicações, na competição interurbana acirrada, bem como em formas compensatórias de cooperação e coordenação interurbana (GRAHAM, 1997; TAYLOR, 2004). Dessa perspectiva, o urbano é não apenas um nível encaixado em hierarquias político-econômicas supraurbanas, mas também é o produto de densas redes interescalares vinculando lugares espalhados por todo o sistema global. Em terceiro lugar, as análises recentes de inspiração regulacionista atrelaram os processos de reestruturação urbana a várias transformações na organização espacial do Estado que estão retirando o acento do nível regulatório nacional e concedendo maior importância às formas tanto supra quanto subnacionais de governança (BRENNER, 2004; JESSOP, 2002). Dessa perspectiva, a escala urbana não é apenas uma arena local para a acumulação de capital global, mas uma coordenada regulatória estratégica onde está se desenrolando, atualmente, uma reestruturação multiescalar da espacialidade do Estado (nacional).

A interpretação apropriada a ser feita sobre as transformações urbanas atuais permanece objeto de consideráveis debates, mas três proposições básicas parecem alicerçar vertentes importantes das tradições de pesquisa acima mencionadas:

1. Os arranjos escalares nacionalizados estão sendo desestabilizados. As formas nacionalizadas de acumulação de capital, de regulação estatal, de urbanização e de lutas sociopolíticas que prevaleceram por todo o mundo capitalista durante o período fordistakeynesiano-Bandung foram desestabilizadas desde meados da década de 1970. Sob as condições atuais, portanto, os "arranjos institucionais que, em um determinado momento, foram congruentes com a escala nacional encontram-se, hoje, mais dispersos por múltiplos níveis espaciais"; entrementes, uma "causalidade multifacetada atua em quase todas as direções entre os vários níveis da sociedade: nações, setores, zonas de livre comércio, regimes internacionais, regiões supranacionais, grandes cidades, e mesmo localidades pequenas mas especializadas $\quad[\ldots]$ (BOYER; HOLLINGSWORTH, 1997, p. 470-2)

2. Estratégias visando reorganizar os arranjos escalares pretéritos estão se proliferando. $\mathrm{Na}$ esteira da crise do fordismo norte-atlântico, inúmeras estratégias sociopolíticas foram mobilizadas com o fito de reorganizar as configurações interescalares pretéritas em esferas importantes da organização político-econômica e da vida cotidiana, incluindo aí a urbanização (SWYNGEDOUW, 1997). Tanto nas cidades quanto para além delas, essas estratégias de reescalonamento são amplamente contempladas como um meio para afastar ou resolver tendências de crise, para administrar problemas regulatórios, para recompor relações de poder, e/ou para estabelecer novas bases geográficas para 0 desenvolvimento capitalista e para a governança político-econômica. Nesse contexto, as cidades e as cidades-região tornaram-se, cada vez mais, locais estratégicos de experimentação regulatória, de inovação institucional e de 
contestação sociopolítica (SCOTT, 1998).

3. Uma relativização de escalas está em curso. As consequências de médio e longo prazo dessas estratégias de reescalonamento para os padrões de desenvolvimento urbano permanecem ainda incipientes, mas elas parecem sinalizar a formação de configurações interescalares novas, nas quais a escala nacional de organização político-econômica estaria sendo significativamente reconstituída. Essa situação foi apropriadamente descrita por Jessop (2000) com uma "relativização da escala". Desse ponto de vista, as transformações espaciais contemporâneas não engendraram um processo unidirecional de globalização, triadização, europeização, decentralização, regionalização ou localização, no qual uma única escala - seja global, triádica, europeia, regional ou local estaria em via de substituir a escala nacional como o nível primordial de coordenação político-econômica. O que estamos testemunhando, na verdade, é uma situação de instabilidade escalar [scalar flux] um abrangente, e contestado, reajustamento das hierarquias escalares pretéritas e das relações interescalares por todo o capitalismo global.

Em resumo, como indica a proliferação de termos e expressões como a "interação localglobal”, o “nexo local-global”, a "glocalização” e "glurbanização", muitos pesquisadores urbanos começaram a refletir conceitualmente sobre a atual onda de reestruturação geoeconômica como uma rearticulação complexa da organização interescalar. A problemática da escala geográfica - sua organização espacial, sua produção social, sua contestação política e sua reconfiguração histórica - foram, portanto, inseridas no âmago da questão urbana. Se a questão urbana tinha anteriormente assumido a forma de debates acerca da especificidade funcional ou da especificidade escalar do urbano no interior de hierarquias interescalares relativamente estáveis, desde os anos 1990 a questão urbana tem sido redefinida na forma de uma questão de escala.

\section{DESAFIOS METODOLÓGICOS ARMADI LHAS DA ANÁLI SE ESCALAR} $\mathbf{E}$

A tarefa de decifrar as hierarquias, mosaicos e redes escalares emaranhadas que emergiram no rastro das transformações geoeconômicas e geopolíticas contemporâneas está ainda em um estágio embrionário, mas já está sendo confrontada por um crescente número de pesquisadores, incluindo aí aqueles ligados aos estudos urbanos e regionais críticos (SHEPPARD; MCMASTER, 2004). No entanto, ainda que os urbanistas mobilizem conceitos escalares com crescente reflexividade, desafios metodológicos importantes associam-se às tarefas de (a) decifrar o papel das cidades no âmbito dos processos contemporâneos de reescalonamento; (b) compreender as implicações dos processos de reescalonamento para os processos de desenvolvimento urbano; e (c) teorizar a natureza dos processos de reescalonamento.

Não menos importante entre esses desafios está o de construir uma gramática conceitual apropriada para representar o caráter processual, dinâmico, e politicamente contestado da escala geográfica e dos arranjos institucionais interescalares. Uma 
reificação da escala parece arraigar-se em vocábulos escalares cotidianos (local, urbano, regional, global, etc) na medida em que esses vocábulos representam processos socioespaciais distintivos (como localização, urbanização, regionalização, nacionalização, globalização, etc) como se eles estivessem permanentemente congelados no espaço geográfico enquanto entidades coerentemente circunscritas e encerradas em si mesma.

De forma relacionada, os vocabulários escalares existentes são pouco adequados para apreender as complexas e sempre cambiantes interconexões e interdependências históricas entre as escalas geográficas. Na medida em que termos como local, urbano, regional e assim por diante são usados para denotar "ilhas" territoriais, supostamente separadas, de relações sociais, eles obscurecem a imbricação mútua e profunda de todas as escalas, e as redes escalares emaranhadas por meio das quais as últimas são constituídas. Essas dificuldades são exacerbadas adicionalmente pela circunstância de que uma parte substancial da divisão do trabalho científico continua sendo organizada de acordo com enfoques escalares - por exemplo, os estudos urbanos, estudos regionais, política comparada, relações internacionais, etc - que tendem a dificultar os esforços no sentido de explorar a dinâmica das relações e transformações interescalares.

Finalmente, mesmo entre aqueles que se preocupam em desenvolver uma abordagem reflexiva e escalar para a economia geopolítica, a teorização da escala tem se tornado cada vez mais contenciosa. Os teóricos divergem, por exemplo, quanto à melhor forma de estabelecer as propriedades essenciais da escala, quanto à sua relação com outros conceitos socioespaciais relevantes, e quanto à sua aplicabilidade ao estudo de processos e relações sociais concretas (ver, por exemplo, AMIN, 2003; BULKELEY, 2005; COLLINGE, 2006; ESCOBAR, 2007; JONAS, 2006; HOWITT, 1998; SHEPPARD; MCMASTER, 2004; SAYRE, 2005). O esclarecimento dessas questões depende de novos debates teóricos, de experimentação metodológica, e de investigações concretas da parte de pesquisadores preocupados com a escala tanto no âmbito dos estudos urbanos como para além deles.

Para os propósitos desse artigo, não tentarei recapitular esses debates teóricos em curso, que promovem agendas teóricas diferentes e que se dirigem para uma ampla gama de questões concretas. Pretendo oferecer, em vez disso, uma breve exposição dos elementos principais da minha própria concepção, que surgiu com minha investigação sobre as geografias da reestruturação da governança urbana na Europa Ocidental pós-1960 (BRENNER, 2004). Como ficará evidente mais adiante, eu discordo de várias perspectivas proeminentes nos debates atuais sobre a teoria socioespacial, incluindo aí (a) a tendência a tratar a escala como uma metáfora genérica da socioespacialidade enquanto tal (MARSTON, 2000); (b) a equiparação da escala com concepções territorialistas do espaço (AMIN, 2003; 2002); (c) a defesa de um abandono dos conceitos escalares em favor de modos topológicos de análise (MARSTON et al, 2005; AMIN, 2002); e (d) a construção da teoria socioespacial com base em assertivas transistóricas ou ontológicas acerca da natureza da vida social (ESCOBAR, 2007; COLLINGE, 2006). Meu propósito aqui, porém, não é o de delinear minhas diferenças com essas perspectivas, mas, antes, de estabelecer uma concepção de escala que eu considero profícua para decifrar os padrões 
contemporâneos de reestruturação urbana e regional.

Se inicialmente as proposições que se seguem adotam o termo escala, elas rapidamente transcendem essa convenção discursiva problemática e elaboram uma gramática conceitual reformulada baseada nas noções processuais de escalonamento e reescalonamento. As escalas, nessa abordagem, não são mais do que resultados temporariamente estabilizados de diversos processos socioespaciais, que devem ser teorizados e investigados nos seus próprios termos. São, em resumo, os processos de escalonamento e reescalonamento, em vez das escalas em si mesmas, que devem ser o foco analítico central para abordagens sobre a questão da escala (SWYNGEDOUW, 1997). Essa reflexão conceitual pretende proporcionar as bases para investigações futuras acerca dos processos de reescalonamento - seja da urbanização, da acumulação de capital, da regulação estatista, ou outras formas socioespaciais que foram investigados pela literatura no campo dos estudos urbanos e regionais revisitada nos parágrafos precedentes. Eu começo com os fundamentos epistemológicos para depois me voltar para os problemas de conceituação e análise.

\section{OITO PROPOSIÇÕES ACERCA DO} REESCALONAMENTO

1. Uma epistemologia crítico-realista de escala. Quais são as condições que possibilitam compreender o mundo social como diferenciado em escalas distintas e relativamente coerentes? Recorro aqui à epistemologia críticorealista (SAYER, 1992), que considera que a inteligibilidade das categorias escalares deriva de um estado de coisas prévio, qual seja, a diferenciação interna de processos sociais específicos em níveis escalares distintos mas interconectados, que por sua vez estruturam percepções, entendimentos e representações, tanto na vida cotidiana quanto nas investigações científico-social. O que quer que eles possam significar - e, como indicamos, essa é uma questão em que há consideráveis discordâncias - os conceitos escalares não são apenas categorias de análise impostas pelo pesquisador ("abstrações conceituais", no sentido de Max Weber). Na verdade, como entendemos aqui, - léxico da escala geográfica (SMITH, 1995) emerge como uma "abstração real" das estruturas, estratégias e transformações que se processam no mundo social (sobre esse último termo, ver SAYER, 1992). Sob o capitalismo tardio, portanto, a necessidade intelectual da questão da escala vincula-se intrinsecamente às mudanças na configuração organizacional e espacial dessa formação social historicamente específica. Se tratamentos anteriores da questão de escala floresceram sob configurações precedentes de desenvolvimento capitalista, suas condições de possibilidade e, portanto, seus fundamentos conceituais, diferem qualitativamente daqueles associados à conjuntura atual, pós-1980, do desenvolvimento desigual do capitalismo global (para um ponto de vista 
radicalmente oposto, com um ponto de partida ontológico, ver MARSTON et al, 2005). , 2005).

2. As escalas resultam da diferenciação e rediferenciação vertical das relações sociais. Mas qual é o ponto de referência concreto para as categorias escalares? O que distingue os conceitos escalares de outros discursos utilizados para descrever formas de organização socioespacial sob o capitalismo? Como concebemos aqui, a diferenciação das relações sociais pela escala decorre do "ordenamento vertical" (COLLINGE, 1999) ou hierarquização espacial das formações sociais. Isso porque, para além da diferenciação "horizontal" ou areal das práticas sociais por todo o espaço geográfico, há também uma diferenciação vertical na qual as relações sociais são hierarquicamente articuladas nos níveis global, supranacional, nacional, regional, metropolitano e/ou local, por exemplo. É relevante dizer que as espacialidades da escala não podem ser entendidas inteiramente em termos dessa dimensão vertical, hierárquica (ver abaixo). Entretanto, o que estou propondo aqui é o forte argumento de que a differentia specifica da organização escalar reside na diferenciação e rediferenciação vertical das relações sociais. A escala, portanto, necessariamente (ou seja, no âmbito de sua definição) pressupõe a estruturação

hierárquica das relações
socioespaciais. Apenas na
ausência completa dessa
estruturação vertical poderia a
visão a-escalar de uma “ontologia
plana” postulada por Marston et al
(2005) tornar-se plausível ${ }^{2}$.

3. As escalas existem porque os processos sociais são escalonados.

As escalas geográficas - as camadas ou níveis distintos no interior das hierarquias interescalares - não são propriedades estáticas, fixas ou permanentes das instituições político-econômicas ou da espacialidade social enquanto tal. Elas são mais bem compreendidas, na verdade, como dimensões socialmente produzidas, e portanto maleáveis, de processos sociais particulares como a produção capitalista, a reprodução social, a regulação estatista, a luta sociopolítica, e assim por diante. Na medida em que qualquer processo social, político, econômico ou forma institucional seja internamente diferenciado em uma hierarquia

\footnotetext{
2 Minha intenção, ao enfatizar a verticalidade das relações escalares, não é negar a importância de formas horizontais de interação e interdependência interescalar - por exemplo, redes de relações entre atores e organizações localizados em cidades, regiões, territórios, etc geograficamente dispersos. Eu argumentaria, contudo, que escalas geográficas e redes de conectividade espacial são aspectos mutuamente constitutivos, ao invés de mutuamente excludentes, da espacialidade social. As redes de conectividade espacial são diretamente estruturadas por processos de escalonamento na medida que esses últimos servem para estabelecer: (a) as unidades espaciais específicas, ainda que frequentemente amorfas, entre as quais as redes em questão são interconectadas; e (b) as órbitas espaciais das redes em questão. Enquanto que a escala geográfica pode estruturar essas relações de conectividade horizontal, as categorias escalares dificilmente proporcionam uma explicação completa das espacialidades multidimensionais inerentes a essas relações.
} 


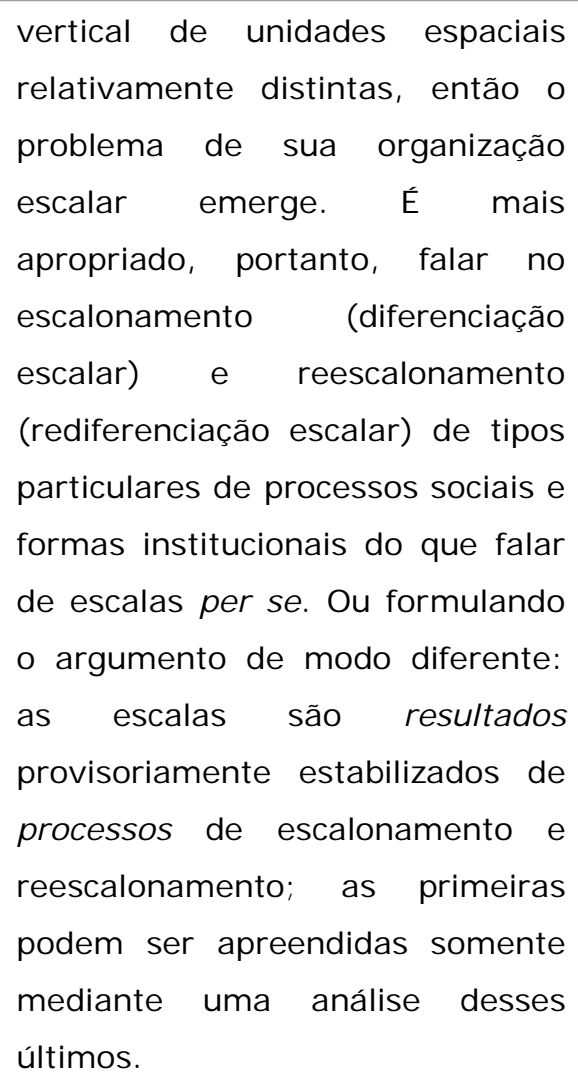

4. As escalas só podem ser apreendidas de modo relacional. As escalas não podem ser consideradas adequadamente como unidades fixas no interior de um sistema de recipientes encaixados definidos por seu tamanho geográfico absoluto (um modelo de escala do tipo "bonecas russas"). A configuração institucional, função(ões), histórias e dinâmicas de qualquer escala geográfica só podem ser apreendidas de forma relacional, com relação aos seus vínculos para cima, para baixo e transversais com outras escalas geográficas situadas no interior de uma configuração interescalar mais abrangente na qual a escala em questão se encontra inserida. Consequentemente, a relevância de termos escalares como global, nacional, regional, urbano e local tende a diferir qualitativamente em função das morfologias escalares historicamente

específicas associadas aos processos sociais ou formas institucionais distintos a que se referem. Desse ponto de vista, é analiticamente impreciso falar de escala no singular - como, por exemplo, em discursos sobre "o" urbano, "o" regional, "o" nacional e "o" global. Essas formulações substancialistas insinuam erroneamente que as escalas individuais contêm uma coerência em si mesmas, e portanto desviam da tarefa essencial de analisar sua co-constituição relacional nos e mediante os processos de estruturação multiescalar.

5. As formas de organização interescalar representam mosaicos, e não pirâmides. A paisagem institucional do capitalismo não é caracterizada por uma pirâmide escalar única e abrangente na qual todos os processos sociais e formas institucionais estão ordenadamente englobados, visto que cada processo social ou forma institucional pode estar associado com padrões distintos de diferenciação escalar. O padrão de diferenciação escalar associado com os estados nacionais, por exemplo, pode apenas parcialmente corresponder àquele das hierarquias urbanas nacionais, que podem, por sua vez, corresponder apenas tendencialmente aos padrões nacionais de circulação financeira ou intercâmbio mercantil. Consequentemente, a arquitetura escalar do capitalismo como um 
todo é composta de um mosaico hierarquias interescalares sobrepostas, emaranhadas, entrelaçadas e desigualmente articuladas cujas unidades são raramente coextensivas ou isomórficas.

6. As configurações interescalares estão inseridas em geografias polimórficas. Os processos de escalonamento e reescalonamento ocorrem em estreita articulação com outras formas de estruturação socioespacial, como a territorialização (delimitação, demarcação), a produção do lugar (aglomeração, reunião), e formação de redes (a construção da conectividade interespacial). A diferenciação escalar de determinado processo social ou forma institucional é, portanto, apenas uma entre muitas dimensões potencialmente relevantes de sua configuração geográfica: a escala é apenas uma faceta da socioespacialidade (BRENNER, 2009). Por essa razão, estudos sobre o escalonamento e reescalonamento devem evitar a armadilha de uma ênfase excessiva na escala, em que os atributos escalares dos processos sociais ou formas institucionais são privilegiados em detrimento de suas outras dimensões socioespaciais.

7. Os processos de reescalonamento são frequentemente condicionados por arranjos pretéritos [pathdependent]. Até hoje, a maior parte da literatura sobre a produção da escala, com seu foco empírico no tumultuado período pós-1970, enfatizou as formas cataclísmicas de transformação escalar que ocorrem durante fases de crise sistêmica. Sob essas condições, as configurações escalares existentes são desmanteladas e reestruturadas; e, após intensas lutas sociopolíticas, hierarquias escalares radicalmente novas podem ser estabelecidas. Contudo, as configurações escalares são não infinitamente maleáveis, mesmo durante fases de restruturação intensas $e$ aceleradas. Além disso, os processos de reescalonamento não implicam a simples substituição de uma configuração interescalar por outra plenamente constituída, ou o completo desaparecimento de algumas escalas na medida que outras as superam. $\mathrm{Na}$ verdade, os processos de reescalonamento geralmente ocorrem mediante a interação inercial e mutuamente transformadora entre os arranjos escalares pretéritos e as estratégias nascentes visando reajustar esses arranjos. Isso significa que, mesmo em meio a intensas pressões no sentido de reestruturar determinada ordem interescalar, as configurações escalares pretéritas podem bloquear certos caminhos de reescalonamento ao circunscrever a produção de novas escalas no interior de determinados parâmetros institucionais e geográficos. As modalidades diferenciais de reestruturação escalar - da incremental e da 
sistêmica até a cataclísmica - sem

dúvida merecem investigação

teórica e empírica muito mais

apurada da parte dos analistas

dos processos de

reescalonamento ${ }^{3}$.

8. Os processos de reescalonamento redefinem as posicionalidades das formações socioespaciais e, portanto, reajustam as geografias e coreografias das relações de poder. $\mathrm{O}$ escalonamento e reescalonamento dos processos sociais medeiam, e são, por sua vez, mediados por relações de poder social profundamente assimétricas e conflituosas (BERNDT, 2000; CASTREE, 2000; HEROD, 1997; SWYNGEDOUW, 1997; SMITH, 1993). Por um lado, o estabelecimento e reorganização das hierarquias escalares criam geografias e coreografias de inclusão/exclusão dominação/subordinação que conferem poder a alguns atores, alianças e organizações em detrimento de outros, de acordo com critérios como classe, gênero, raça/etnicidade e nacionalidade.

\footnotetext{
3 Collinge (1999) sugere que a seleção de uma escala dominante e, de forma mais geral, a evolução das hierarquias escalares são ajustadas para serem "ótimas" para os propósitos da acumulação. Enquanto que análise de Collinge proporciona uma crítica estruturalista pertinente de certas vertentes voluntaristas dentro da teoria da regulação, o pressuposto de que a evolução escalar refletirá os requerimentos historicamente cambiantes da acumulação de capital é problemático. Como sugere a literatura sobre pathdependency, configurações institucionais subótimas frequentemente se cristalizam devido às vantagens maiores ("retornos crescentes") que ocorrem à medida que elas se tornam mais difundidas (ARTHUR, 1994). Ademais, é fundamental explorar as maneiras pelas quais os processos de reescalonamento são também condicionados por: (a) a inércia (relativa) das configurações escalares existentes e (b) as estratégias políticas e o equilíbrio mutante das relações de classe e outras forças sociais contraditórias.
}

Dessa forma, os processos de reescalonamento podem modificar as posicionalidades de formas socioespaciais particulares, ou seja, suas posições relacionais no âmbito do sistema mais amplo de desenvolvimento espacial desigual do capitalismo global (SHEPPARD, 2002). Por outro lado, as hierarquias escalares podem operar não apenas como arenas de lutas por poder social, mas também como o próprio objetivo dessas lutas, na medida em que essas hierarquias são confrontadas e desestabilizadas no curso de lutas e conflitos sociopolíticos por posicionalidade. Isso porque, como sugeriu Swyngedouw (1997, p. 141), “o rearranjo e reorganização contínuos das escalas espaciais são parte integrante das estratégias e lutas sociais por controle e ganho de poder". Igualmente, na formulação concisa de Smith (1993, p. 101), “a escala de luta e a luta pela escala são dois lados da mesma moeda". O esclarecimento das condições histórico-geográficas particulares sob a quais as hierarquias escalares podem tornar-se o próprio objetivo - em vez de meramente o contexto das lutas sociais por posicionalidade é uma tarefa que aguarda investigações mais sistemáticas.

É pertinente reiterar uma conclusão analítica decisiva, ainda que aparentemente paradoxal, que decorre das proposições acima: as "escalas" não 
existem enquanto tal. Considerando minha ênfase no (a) caráter plural, polimórfico e heterogêneo da socioespacialidade; (b) na relacionalidade inerente a cada camada das hierarquias interescalares; e (c) no caráter profundamente dinâmico e processual das configurações interescalares, a linguagem um tanto estática $e$ monodimensional de "escala" parece cada vez mais inadequada. Como indicado anteriormente, não estamos lidando com uma economia política de escalas fixas, distintas, singulares e encaixadas, mas, antes, com uma multiplicidade de economias políticas escalonadas [scaled political economies] que estão implicadas em, e por sua vez são produtoras de, padrões diversos e entrelaçados de diferenciação e rediferenciação escalar. A tarefa, portanto, não é meramente a de reconhecer o caráter escalar diferenciado da vida político-econômica, mas, de modo mais abrangente, (a) explorar as dinâmicas sociais diversas nas quais e por meio das quais as configurações político-econômicas escalares são ativamente produzidas e continuamente transformadas no curso do desenvolvimento geo-histórico capitalista; e (b) rastrear as maneiras pelas quais essas ordens políticoeconômicas escalares estruturam (isto é, ao mesmo tempo constrangem e possibilitam) relações sociais de poder, dominação, exploração e luta. Desse ponto de vista, a expressão "nova economia política da escala" (KEIL; MAHON, 2009) deve ser entendida como uma referência abreviada aos esforços recentes para decifrar o contínuo escalonamento e reescalonamento da vida econômico-política sob o capitalismo. Pode-se afirmar que noção de economia política escalonada [scaled political economy] proporciona um registro mais preciso para a abordagem teórica aqui proposta, visto que coloca em relevo que o ponto focal para a investigação escalar não são as escalas em si, mas sim os processos de escalonamento (diferenciação escalar) e reescalonamento (rediferenciação escalar) que alicerçam as dinâmicas de evolução institucional e luta sociopolítica sob o capitalismo moderno.

\section{OS LIMITES DO} REESCALONAMENTO?

$\begin{array}{ccr}\text { Ainda que } & \text { as proposições } \\ \text { precedentes } & \text { requeiram } & \text { maior }\end{array}$ refinamento com base em pesquisas concretas acerca da reestruturação urbana e regional, creio que elas ofereçam uma alternativa profícua aos escritos mais recentes que neutralizam ou estendem excessivamente os conceitos escalares (MARSTON, 2000), assim como às propostas desconstrutivas de abolir ou abandonar inteiramente esses conceitos (MARSTON et al, 2005; COLLINGE, 2006). Além disso, a discussão precedente desmantela qualquer abordagem da questão urbana que conceba seu objeto como um espaço delimitado, "local" ou mesmo "regional". Evidentemente, são necessários estudos adicionais situados em diferentes níveis de abstração-concretude a fim de lidar com uma série de tarefas analíticas relevantes que decorrem dessa concepção processual e multiescalar. Mais premente entre essas tarefas são: (a) teorizar os mecanismos pelos quais os processos de urbanização contemporâneos estão sendo escalonados e reescalonados; (b) explorar as 


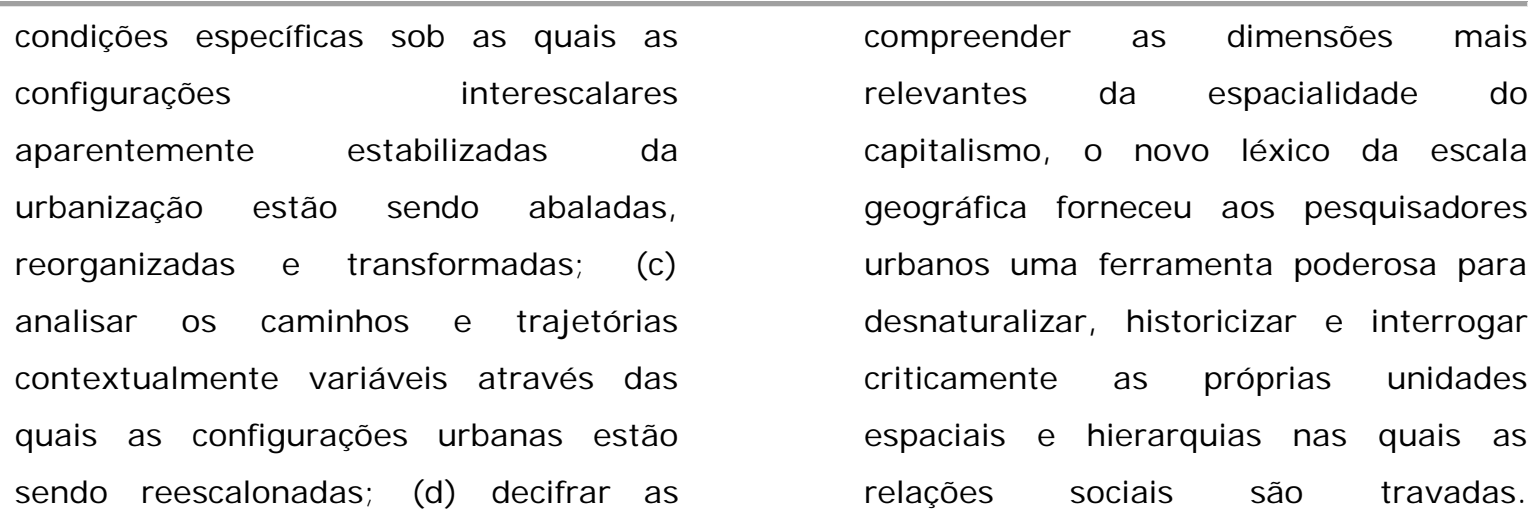
diversas estratégias políticas, forças sociais e alianças territoriais que se mobilizam em torno, ou contra, estratégias particulares para reorganizar as escalas dos processos de urbanização; e (e) examinar a interação entre os processos de escalonamento e reescalonamento e outros processos de reestruturação socioespacial (como a produção do lugar, a territorialização e a formação de redes) ao longo da geohistória da urbanização capitalista. A proliferação de debates explícitos sobre a escala geográfica e o reescalonamento durante os anos 1990 pode ser entendida como uma extensão e um refinamento significativos das abordagens espacializadas acerca da economia política urbana e regional que se desenvolveram na década precedente, estimuladas em grande medida pelo abalo das hierarquias e interdependências escalares associadas ao capitalismo organizado no período pós-1970. Posteriormente, e não apenas no âmbito dos estudos urbanos $\mathrm{e}$ regionais, as discussões sobre a questão da escala proporcionaram uma gramática conceitual mais precisa para analisar rediferenciação contínua e hierárquica das relações socioespaciais durante um período particularmente volátil na geohistória do capitalismo. Ao passo que um sofisticado vocabulário analítico já fora desenvolvido nos anos 1980 para

Consequentemente, os debates recentes sobre a questão da escala proporcionaram aos urbanistas e outros economistas geopolíticos críticos lentes analíticas importantes por meio das quais começar a decifrar as geografias dos processos de reestruturação contemporâneos.

$\mathrm{Na}$ minha leitura, as contribuições recentes para a análise da produção e transformação da escala possuem implicações particularmente relevantes para o campo dos estudos urbanos, cuja unidade de análise permanece profundamente ambígua, mesmo após quase um século de debate acerca da natureza da questão urbana. Como as proposições assinaladas acima indicam, eu alertaria contra a tendência de estender excessivamente os conceitos escalares nos estudos urbanos ou em qualquer outro campo da análise socioespacial. Isso porque as estruturações escalares do espaço social (baseadas em relações hierarquização entre unidades verticalmente diferenciadas) são analiticamente distintas de outras formas de estruturação socioespacial, como a produção do lugar, a localização, a territorialização e a formação de redes (BRENNER, 2009; JESSOP et al, 2008). Como foi sugerido, o léxico da escala geográfica é mais potente quando seus limites analíticos são explicitamente 


$\begin{array}{ll}\begin{array}{l}\text { compreendidos (BRENNE, 2001). } \\ \text { Paradoxalmente, uma concepção }\end{array} & \begin{array}{l}\text { escalares radicalmente diferentes } \\ \text { fundamentados em princípios de }\end{array} \\ \begin{array}{l}\text { analiticamente mais estreita de escala } \\ \text { facilita uma aplicação mais abrangente, }\end{array} & \begin{array}{l}\text { democracia radical, emancipação e } \\ \text { justiça socioespacial (MAYER, 2007). } \\ \text { mas ao mesmo tempo mais precisa, }\end{array} \text { Nesse sentido, a crescente proeminência } \\ \text { desse conceito às vicissitudes da } & \text { dos conceitos escalares na teoria e } \\ \text { restruturação capitalista mundial. } & \text { pesquisa urbanas contemporâneas pode } \\ \text { Embora o capitalismo há muito } & \text { ser entendida como uma “abstração real” } \\ \text { diferencia-se em hierarquias escalares, o } & \text { das contínuas lutas interescalares: é } \\ \text { atual período de reestruturação global } & \text { precisamente porque a configuração da } \\ \text { induzida pela crise é marcado por } & \text { escala geográfica tornou-se um foco tão } \\ \text { transformações } & \text { importante da contestação sociopolítica } \\ \text { profundas da organização escalar. Ao } & \text { contemporânea que os urbanistas e } \\ \text { longo das últimas três décadas, o projeto } & \text { outros cientistas sociais que refletem } \\ \text { geoeconômico do neoliberalismo - com } & \text { sobre o espaço tornaram-se tão } \\ \text { sua ênfase na mobilidade do capital, nas } & \text { sensíveis, nos anos recentes, à sua } \\ \text { relações de mercado sem restrições, na } & \text { importância metodológica profunda. }\end{array}$
mercantilização intensificada - resultou em um enorme assalto contra as escalas estabelecidas de regulação sociopolítica e em uma tentativa agressiva de forjar novas hierarquias escalares mundiais nas quais a lógica da competição desenfreada possa ser institucionalizada. Essas tendências tiveram ramificações significativas para as cidades e para os sistemas de governança urbana, que se tornaram alvos estratégicos dos projetos neoliberais de destruição criativa espacial e institucional (BRENNER; THEODORE, 2002). Ao mesmo tempo, tanto nas cidades como para além delas, movimentos de oposição que lutam para obstruir ou reverter a investida neoliberal contemporânea começaram igualmente a mobilizar a escala geográfica de formas estratégias e frequentemente bastante criativas - seja saltando escalas para escapar da hegemonia das práticas institucionais dominantes, seja mobilizando apoio para projetos de regulação que objetivam socializar o capital em escalas particulares, seja, finalmente, vislumbrando arranjos

\section{Agradecimento}

Sou grato aos editores da revista Critical Planning pela oportunidade de contribuir nessa edição especial. Esse texto deriva de um esboço de um livro em andamento, hesitantemente intitulado A thousand leaves: Urban Theory and the Scale Question. 


\section{REFERÊNCI AS BI BLI OGRÁFICAS}

AMIN, Ash. Regions unbound: towards a new politics of place. Geografiska Annaler, Série B, 86(1), 3344, 2003.

AMIN, Ash. Spatialities of globalization. Environment and Planning A, n.34(3), 385-399, 2002.

ARTHUR, Brian W. Increasing returns and path dependence in the economy. Ann Arbor: University of Michigan Press, 1994.

BERNDT, Christian. The rescaling of labour regulation in Germany: from national and regional corporatism to intrafirm welfare? Environment and Planning A, n.32(9), p.1569-1592, 2000.

BOYER, R., HOLLINGSWORTH, J. Rogers. From national embeddedness to spatial and institutional nestedness. In: Contemporary capitalism: The embeddedness of institutions. New York: Cambridge University Press, 1997.

BRENNER, NEIL. A thousand leaves: notes on the geographies of uneven development. In: KEIL, R.; MAHON, R. (org.). Leviathan undone? Towards a political economy of scale. Vancouver: University of British Columbia Press, 2009. p. 27-49.

BRENNER, Neil. New state space: Urban governance and the rescaling of statehood. Oxford e New York: Oxford University Press, 2004.

BRENNER, Neil. The limits to scale? Methodological reflections on scalar structuration. Progress in Human Geography, n.25(4), p. 591-614, 2001.

BRENNER, Neil; THEODORE, Nik (org.). Spaces of neoliberalism: Urban restructuring in North America and
Western Europe. Oxford, UK e Cambridge, MA: Blackwell, 2002.

BULKELEY, Harriet. Reconfiguring environmental governance: towards a politics of scales and networks. Political Geography, n.24(8), p. 875-902, 2005.

CASTELLS, Manuel. Is there an urban sociology? In: Urban sociology: critical essays. PICKVANCE, C.G (org.). New York: St. Martin's Press, 1976. p.33-59.

CASTELLS, Manuel. The urban question. Cambridge, MA: MIT Press and Edward Arnold, 1977.

CASTREE, Noel. Geographic scale and grass-roots internationalism: the Liverpool dock dispute, 1995-1998. Economic Geography, n.76(3), p.272292, 2000

COLLINGE, Chris. Flat ontology and the deconstruction of scale: a response to Marston, Jones and Woddward. Transactions of the Institute of British Geographers, n.31(2), p. 244-251, 2006.

COLLINGE, Chris. Self-organization of society by scale: a spatial reworking of regulation theory. Environment and Planning D:Society and Space, n.17(5), p.557-574, 1999.

DEAR, Michael; SCOTT, Allen J.(org.). Urbanization and urban planning in capitalist society. London e New York: Methuen, 1982.

ESCOBAR, Arturo. The “ontological turn" in social theory: a commentary on Human geography without scale", by Sallie Marston, John Paul Jones III and Keith Woodward. Transactions of the Institute of British Geographers, n.32(1), p.106-111, 2007.

FRIEDMANN, John; WOLFF, Goetz. World city formation: an agenda for research and action. International Journal 
of Urban and Regional Research, n.6(3), p.309-344, 1982.

GOTTDIENER, Mark. The social production of urban space. Austin: University of Texas Press, 1985.

GRAHAM, Stephen. Cities in the realtime age: the paradigm challenge of telecommunications to the conception and planning of urban space. Environment and Planning A, n.29(1), p.105-127, 1997.

HARVEY, David. The urban experience. Oxford and Baltimore: Basil Blackwell e John Hopkins University Press, 1989.

HARVEY, David. The limits to capital. Oxford e Chicago: Blackwell and University of Chicago Press, 1982.

HEROD, Andrew. Labor's spatial praxis and the geography of contract bargaining un the US east coast longshore industry, 1953-1989. Political Geography, n.16(2), p.145-169, 1997.

HOWITT, Richard. Scale as relation: musical metaphors of geographical scale. Area, n.30(1), p.49-58, 1998.

JESSOP, Bob. The future of the capitalist state. Cambridge, UK: Polity, 2002.

JESSOP, Bob. The crisis of the national spatio-temporal fix and the tendential ecological dominance of globalizing capitalism. International Journal of Urban and Regional Research, n.24(2), p.323-360, 2000.

JESSOP, Bob. The narrative of enterprise and the enterprise of narrative: place-marketing and the entrepreneurial city. In: The entrepreneurial city. HALL, T.; HUBBARD, P. (org), p. 77-102. London: John Wiley \& Sons, 1998.

JESSOP, Bob; BRENNER, Neil; JONES, Martin. Theorizing sociospatial relations.
Environment and Planning D: Society and Space, n.26(3), p.389-401, 2008.

JONAS, Andrew E.G. Pro scale: further reflections on the "scale debate" in human geography. Transactions of the Institute of British Geographers, n.31(3), p.399-406, 2006.

KEIL, Roger; MAHON, Rianne (org.). Leviathan undone? Towards a political economy of scale. Vancouver: University of British Columbia Press, 2009.

KNOX, Paul; TAYLOR, Peter (org). World cities in a world system. Cambridge, IK and New York: Cambridge University Press, 1995.

LEFEBVRE, Henri. State, space, world: Selected essays. BRENNER, Neil; ELDEN, S.(org). Minneapolis: University of Minnesota Press, 2009.

LEFEBVRE, Henri. The Right to the City. In: Henri Lefebvre, Writings on Cities. Traduzido por E. Kofman e E. Lebas, p.63-181. Cambridge, MA: Blackwell, 1996.

LEFEBVRE, Henri. The explosion: Marxism and the French upheaval. Trduzido por A. Ehrenfeld. New York: Monthly Review Press, 1969.

LIPIETZ, Alain. The national and the regional: their autonomy vis-à-vis the capitalist world crisis. In: Transcending the state-global divide. PALAN, R.P.; GILLS, B.(org.). Boulder: Lynne, 1994.

MARSTON, Sallie A. The social construction of scale. Progress in Human Geography, n.24(2), p.219-242, 2000.

MARSTON, Sallie A.; JONES III, J ohn Paul; WOODWARD, Keith. Human geography without scale. Transactions of the Institute of British Geographers, n.30(4), p.416-432, 2005.

MASSEY, Doreen. Spatial Divisions of Labour: Social structures and geography 
of production. New York e London: Methuen e Macmillan, 1985.

MAYER, Margit. Contesting the neoliberalization of urban governance. In: Contesting neoliberalism: Urban frontiers. LEITNER, H; PECK, J.; SHEPARD, E. (org.), p.90-115. New York: Guilford, 2007.

PECK, Jamie; TICKELL, Adam. Searching for a new institutional fix: The after-Fordist crisis and the global-local Disorder. In: Post-Fordism: A reader. AMIN, Ash (org.), p.280-315. Cambridge, MA: Blackwell, 1994.

SAUNDERS, Peter. Social theory and the urban question. 2.ed. London: Hutchinson, 1986.

SAYER, Andrew R. Method in social science. 2.ed. London: Routledge, 1992.

SCOTT, Allen J. Regions and the world economy: The coming shape of global production, competition and political order. Oxford: Oxford University Press, 1998.

SCOTT, Allen J. The urban land nexus and the state. London: Pion, 1980.

SCOTT, Allen J.; STORPER, Michael (org.). Production, work, territory: The geographical anatomy of industrial capitalism. London: Allen \& Unwin, 1986.

SHEPPARD, Eric. The space and times of globalization: place, scale, networks and positionality. Economic Geography, n. 78(3), p. 307-330, 2002.

SHEPPARD, Eric; MCMASTER, Robert (org.). Scale and geographic inquiry: Nature, society and method. Malden, MA: Blackwell, 2004.

SMITH, Neil. Remaking scale: competition and cooperation in prenational and postnational Europe. In: Competitive European peripheries. ESKELINEN, H.; SNICKARS, F. (org.), p. 59-72. Berlim: Springer Verlag, 1995.
SMITH, Neil. Homeless/global: Scaling places. In: Maping the futures: Local cultures, global change. BIRD, J. et al (org.), p. 87-119. New York: Routledge, 1993.

SMITH, Neil. Geography, difference and the politics of scale. In: Postmodernism and the social science. DOHERTY, E.; GRAHAM, E.; MALEK, M. (org.), p.57-79. London: Macmillan, 1992.

SOJA, Edward W. Postmetropolis: Critical studies of cities and regions. Oxford, UK e Cambridge, MA: Blackwell, 2000.

SOJA, Edward W. Postmodern geographies: The reassertion of space in critical social theory. London e New York: Verso, 1989.

SOJA, Edward W. Economic restructuring and the internationalization of Los Angeles. In: The capitalist city. SMITH, M.P.; FEAGIN, J.R. (org.), p.178198. Cambridge, MA: Clackwell, 1987.

STORPER, Michael; SCOTT, Allen J.(org.). Pathways of industrialization and regional development. New York: Routledge, 1992.

STORPER, Michael; WALKER, Richard. The capitalist imperative: Territory, technology and industrial growth. Cambridge, MA: Blackwell, 1989.

SWYNGEDOUW, Erik. Neither global nor local: "glocalization" and the politics of scale. In: Space of Globalization. COX, K. R.(org.), p. 137-166. New York: Guilford Press, 1997.

SWYNGEDOUW, Erik. The Mammon quest: "glocalisation", interspatial competition and the money order: the construction of new scales. In: Cities and regions in the new Europe. DUNFORD, M.; KAFKALAS, G. (org.), p.39-68. London: Belhaven Press, 1992. 
TAYLOR, Peter J. World city network: A global urban analysis. London: Routledge, 2004.

TAYLOR, Peter J. World cities and territorial states: the rise and fall of their mutuality. In: World cities in a worldsystem. KNOX, P.; TAYLOR, P. J. (org.), p.48-62. Cambridge, UK e New York: Cambridge University Press, 1995. 